\title{
Effect of a three month course of ciprofloxacin on the outcome of reactive arthritis
}

T Yli-Kerttula, R Luukkainen, U Yli-Kerttula, T Möttönen, M Hakola, M Korpela, M Sanila, J Parviainen, J Uksila, R Vainionpää, A Toivanen

Department of

Medicine, Turku

University, Finland

T Yli-Kerttula

T Möttönen

A Toivanen

Department of

Medical Microbiology,

Turku University

J Uksila

Department of

Virology, Turku

University

$R$ Vainionpää

Satalinna Hospital,

Finland

R Luukkainen

M Sanila

Department of

Medicine, Section of

Rheumatology,

Tampere University

Hospital, Finland

U Yli-Kerttula

M Korpela

Jyväskylä Central Hospital, Finland M Hakola

Stat-X, Finland

J Parviainen

Correspondence to: Dr Timo Yli-Kerttula, Department of Medicine, Turku University,

Kiinamyllynkatu 4-8, FIN-20520 Turku, Finland Email:

timo.yli-kerttula@utu.fi

Accepted for publication 31 January 2000

\begin{abstract}
Background-Treatment of reactive arthritis $(\operatorname{ReA})$ with antibiotics has so far remained controversial. Eradication of the causative microbe appears logical, but short term antibiotic treatment has no beneficial effect on the outcome of ReA.

Objective-To evaluate the effect of a three month course of ciprofloxacin on ReA.

Methods-In a randomised, double blind, placebo controlled trial, between December 1992 and February 1996, 71 patients with acute $\operatorname{ReA}$ triggered by a gastrointestinal or a urogenital infection were randomly assigned to receive ciprofloxacin $500 \mathrm{mg}$ or placebo twice daily for three months. Patients were assessed at study entry, at 6 weeks, 3 months, 6 months, and 12 months. Sixty two patients were valid for the efficacy analysis. The primary outcome measures were erythrocyte sedimentation rate, number of swollen joints, patients self assessment, and complete recovery.
\end{abstract}

Results-Adverse events were mostly mild and occurred in both treatment groups. There were no statistically significant differences in any of the primary or secondary efficacy variables between the study groups at baseline or during the 12 month follow up. All primary outcome measures indicated that the condition of the patients improved during the study.

Conclusion-Both groups tended to recover. Ciprofloxacin, given as a three month course, had no advantage over placebo treatment.

(Ann Rheum Dis 2000;59:565-570)

Reactive arthritis $(\operatorname{ReA})$ is a non-purulent joint inflammation developing after an infection elsewhere in the body. Mostly it is triggered by enteric infections due to yersinia, campylobacter, salmonella, and shigella species or by sexually transmitted microbes, such as Chlamydia trachomatis, Ureaplasma urealyticum, or gonococcus. ${ }^{12}$ The pathogenesis of ReA is incompletely known, but the triggering infection has a central role. Genetic factors, especially the class I major histocompatibility complex molecule HLA-B27, render the subject susceptible to the disease. ${ }^{1}$

Newly diagnosed ReA usually has a self limiting course, lasting from a few weeks to several months. However, in $20-70 \%$ of patients the disease is prolonged, with arthritic recurrences and other manifestations, such as enthesopathy, sacroiliitis, and urogenital or eye inflammations. ${ }^{3-8}$ Radiographic sacroiliitis is more likely to appear in those with severe, chronic, or recurrent disease. The incidence of sacroiliitis is higher in patients with classic Reiter's syndrome than in patients with enteroarthritis. ${ }^{9}$ It is generally accepted that in some patients ReA may progress further to ankylosing spondylitis. ${ }^{10}{ }^{11}$

Several findings raise the question whether the causative microbe remains for a long time in the body of patients with ReA. In yersinia triggered $\mathrm{ReA}$, persistence and maturation of IgA class antibodies suggest that the microbe or its antigenic components maintain the immune response in the intestinal mucosa or close to it. ${ }^{12} 13$ Findings by HoogkampKorstanje et al indicate persistence of yersinia bacteria in the submucosa of the gut and adjacent lymph nodes. ${ }^{14}$ Immune complexes composed of yersinia structures and specific antibodies have been shown in the peripheral blood and synovial fluid of patients with ReA. ${ }^{15} 16$ Further, yersinia, ${ }^{15}$ salmonella, ${ }^{17}$ shigella, ${ }^{18}$ and chlamydia components as well as chlamydial DNA and $\mathrm{rRNA}^{19-22}$ have been detected in the synovial fluid of patients with ReA.

The conventional pharmacological treatment of ReA comprises non-steroidal antiinflammatory drugs (NSAIDs) and intraarticular or systemic steroids. Sulfasalazine is effective in the treatment of chronic ReA. ${ }^{23}$ Eradication of possibly persisting triggering microbes would appear a logical approach. Yet, the place of antibiotics in the treatment of reactive arthritis is still controversial. According to Frydén et al, short term antibiotic treatment has no beneficial effect on the clinical outcome of ReA associated with enteric infection. ${ }^{24}$ In Yersinia enterocolitica infection, antibiotic treatment shortened the duration of IgG antibody persistence in patients with uncomplicated enterocolitis, but not in those with ReA. ${ }^{25}$ In a placebo controlled study of patients with acute ReA, the duration of $C$ trachomatis triggered arthritis was shorter in those treated with a three month course of lymecycline than in those treated with placebo. In patients with enteroarthritis no difference was observed. ${ }^{26}$ In our previous study a three month course of ciprofloxacin had a favourable effect on some clinical variables in chronic ReA, but the overall effect was not convincing. ${ }^{27}$

Two reports show a beneficial effect of antibiotic treatment on ReA. In the first, antibiotic treatment of yersinia triggered arthritis for four to six weeks resulted in clinical improvement 
Table 1 Baseline characteristics of the patients with reactive arthritis (valid for efficacy and safety). Results are shown as means (SD)

\begin{tabular}{lll}
\hline & $\begin{array}{l}\text { Ciprofloxacin group } \\
(n=30)\end{array}$ & $\begin{array}{l}\text { Placebo group } \\
(n=32)\end{array}$ \\
\hline Age (years) & $37.1(13.4)$ & $35.7(11.2)$ \\
Duration of disease (days) & $39(27)$ & $52(69)$ \\
Height $(\mathrm{cm})$ & $172(10)$ & $174(8)$ \\
Weight $(\mathrm{kg})$ & $75(12)$ & $74(13)$ \\
BMI & $25.4(4.3)$ & $24.7(4.2)$ \\
Sex & & \\
$\quad$ Female & 13 & 14 \\
$\quad$ Male & 17 & 18 \\
Number of swollen joints & $3.7(1.8)$ & $3.3(1.6)$ \\
Joint tenderness score $=$ Ritchie index & $6.7(3.3)$ & $5.9(2.9)$ \\
Joint swelling score & $5.5(2.7)$ & $5.1(2.9)$ \\
Morning stiffness (min) & $48(29)$ & $49(28)$ \\
ESR ${ }^{\star}(\mathrm{mm} / 1$ st h) & $55(28)$ & $67(26)$ \\
CRP $(\mathrm{mg} / 1)$ & $67(56)$ & $52(40)$ \\
Haemoglobin (g/l) & $130(14)$ & $123(15)$ \\
Leucocytes $\left(10^{9} / 1\right)$ & $8.9(2.1)$ & $8.9(2.3)$ \\
HLA-B27 positive $(\%)$ & $22(73)$ & $27(84)$ \\
\hline
\end{tabular}

${ }^{\star} \mathrm{BMI}=$ body mass index $\mathrm{ESR}=$ erythrocyte sedimentation rate; $\mathrm{CRP}=\mathrm{C}$ reactive protein.

accompanied by disappearance of the yersinia antigen in intestinal biopsy specimens and of serum IgA antibodies to yersinia. ${ }^{28}$ The interesting study of Bardin et al showed that relapses of postvenereal arthritis in patients with Reiter's disease were reduced when new urogenital infections were treated early and vigorously with antibiotics. ${ }^{29}$

Ciprofloxacin is a synthetic 4-quinolone derivative with bactericidal activity against a wide range of Gram negative and Gram positive micro-organisms. Thus it is efficacious against most microbes linked to the pathogenesis of reactive arthritis, such as yersinia, salmonella, and campylobacter, and has a moderate to good efficacy against chlamydia. ${ }^{30}$ It also has an effective penetration into the inflamed tissues. Therefore, it would be a reasonable therapeutic option for the treatment of $\operatorname{ReA}$.

In a double blind, randomised study we evaluated the efficacy, safety, and tolerability of long term treatment with ciprofloxacin compared with placebo in acute ReA triggered by a gastrointestinal or urogenital infection.

\section{Methods}

STUDY DESIGN

This study was a randomised, double blind, placebo controlled clinical trial. Seventy one patients gave informed consent and participated in the study. The protocol was approved by the ethics committees in each participating centre.

\section{PATIENT POPULATION}

Adult outpatients or inpatients of Turku University Central Hospital, Tampere University Central Hospital, Satalinna Hospital, or Jyväskylä Central Hospital who had clinically evident acute ReA were recruited for the study. Thirty six patients were randomly assigned to the ciprofloxacin group and 35 to the placebo group.

No significant differences $(\mathrm{p}<0.05)$ in demographic data or clinical and laboratory variables were found between the two treatment groups (table 1). Forty nine patients $(79 \%)$ were HLA-B27 positive-22 (73\%) in the ciprofloxacin and $27(84 \%)$ in the placebo group (valid for efficacy analysis).
The patients had acute ReA triggered by a urogenital or gastrointestinal infection. A diagnosis of ReA was made if patients presented with a clinical picture of an asymmetrical arthritis and symptomatic enteritis or urethritis a few days to a few weeks before the onset of arthritis. Age at study entry had to be at least 18 years and the patients had to be able to take the study drug properly. NSAIDs and local glucocorticoid treatment were allowed but no systemic glucocorticoids, disease modifying antirheumatic drugs, or other antimicrobial drugs than the test drug. The duration of articular disease could not be longer than three months. All patients gave their informed consent.

Exclusion criteria included allergy to quinolone derivatives, pregnant or lactating women or women in whom pregnancy could not be ruled out, patients requiring concomitant antimicrobial treatment for more than 10 days during or before the study, patients receiving antirheumatic drugs or systemic steroids, and patients with other inflammatory joint diseases.

DRUG ADMINISTRATION

Patients were randomly assigned to receive ciprofloxacin $500 \mathrm{mg}$ or placebo, which were supplied in coded, identical tablets for oral administration. The patient was instructed to take one tablet of test drug (ciprofloxacin 500 mg tablet or matching placebo) twice daily for three months. Reasons for premature termination were an interruption interval of more than two weeks, less than $85 \%$ of the drug taken, severe side effects, medical or surgical conditions which required removal from the study, or the patient's reluctance to continue the study.

\section{CONCOMITANT TREATMENT}

Patients were allowed to continue or receive other drugs provided that these were not disease modifying antirheumatic drugs or immunosuppressive drugs. Concomitant treatment with an appropriate other antimicrobial drug, if needed, was allowed for up to 10 days. If the concomitant antimicrobial treatment continued for more than 10 days, the patient was excluded from the study. Antacids containing aluminium or bismuth were allowed to be taken only if they were given two hours before or after the test drug administration. All concomitant drugs were identified and recorded in the case report form at each visit.

\section{CLINICAL ASSESSMENTS}

Patients were assessed at study entry, at 6 weeks, 3 months, 6 months, and 12 months. The following variables were evaluated: Ritchie articular index, ${ }^{31}$ the number and scoring of swollen joints, duration of morning stiffness, and the following variables using a $100 \mathrm{~mm}$ visual analogue scale (VAS) as evaluated by the patient: global assessment, articular pain at movement, articular pain at rest, difficulty of movement and severity of morning stiffness, overall improvement as evaluated by the doctor using a $100 \mathrm{~mm}$ VAS. 
LABORATORY ASSESSMENTS

The following laboratory values were determined at each visit according to standard methods: erythrocyte sedimentation rate (ESR), serum $\mathrm{C}$ reactive protein (CRP), blood haemoglobin concentration, white blood cell (WBC) count, thrombocyte count, serum antibody titres against the triggering microbe, and urine analysis. In addition, all patients were typed for HLA-B27. A serum sample from each follow up visit was stored at $-20^{\circ} \mathrm{C}$, and after completion of the clinical study, as a screening test, levels of serum antibodies against the most usual triggering microbes in ReA were determined from paired serum samples taken at the beginning of the study and at six weeks. The antibody titres against the triggering microbe were then followed up from samples taken at later visits $(3,6$, and 12 months).

Serum antibodies of $\operatorname{IgM}, \operatorname{IgA}$, and IgG class against salmonella, yersinia, and campylobacter were determined by enzyme immunoassay. Antibodies to Salmonella enteritidis and $S$ typhimurium were measured with combined lipopolysaccharide as antigens. This method can also detect antibodies against other salmonellae. ${ }^{32}$ For yersinia antibodies, sodium dodecyl sulphate extracts of $Y$ enterocolitica $\mathrm{O}: 3, Y$ enterocolitica $\mathrm{O}: 9, Y$ pseudotuberculosis I, and $Y$ pseudotuberculosis III were used as antigens. ${ }^{33}$ Campylobacter antibodies were determined by using an acid glycine extract of Campylobacter jejuni as antigen. ${ }^{34}$ Antibody levels at least four standard deviations higher than the mean of normal control subjects were regarded as positive. Chlamydia trachomatisspecific IgG antibodies were measured by enzyme immunoassay using elementary bodies of $C$ trachomatis $\mathrm{L} 2$ strain as antigen according to Finn et $a l,{ }^{35}$ and an indirect microimmunofluorescence assay was used to study IgG and IgA antibodies against $C$ pneumoniae.

Immunoglobulin concentrations were determined at study entry, 3 months, and 12 months. Alanine aminotransferase activity and serum creatinine concentration were determined before, during ( 6 weeks), and after ( 3 months) administration of the study drug.

The following analysis of synovial fluid from swollen joints was carried out: bacteriological culture and Gram stain, WBC and differential count, crystals, proteins, and lactate.

Fecal culture for salmonella, shigella, campylobacter, and yersinia was examined at the start of the study.

An electrocardiogram was registered in order to observe the possible changes of myocarditis at the acute phase of the disease.

\section{RADIOGRAPHIC EVALUATION}

Radiographs were taken according to the investigators' decision. Sacroiliac joint radiographs were taken if the patient had chronic low back pain and peripheral joint radiographs were taken in cases of severe, prolonged joint swelling.
SAMPLE SIZE

Four variables were used as primary outcome measures: (a) ESR, (b) number of swollen joints, (c) patient's global assessment (VAS), and (d) complete recovery. Recovery was defined as normal findings by the patient's global assessment, ESR, serum CRP, WBC count, and clinical examination (no swollen joints). Secondary variables were Ritchie's index, swelling index, serum CRP, overall improvement as evaluated by the doctor (VAS), blood haemoglobin, and blood leucocyte count.

The sample size was calculated with the formula $\mathrm{n}=2 \times \mathrm{SD}^{2} \times \mathrm{f}(\alpha, \beta) / \Delta^{2}$. The difference $\Delta$ $=20 \mathrm{~mm}$ in the mean values of ESR between the two groups will not be overlooked with the power $1-\beta=0.80$ and two sided significance level $\alpha=0.05$. The standard deviation (SD) of ESR is assumed to be $26.0 \mathrm{~mm}$, based on previous studies. With these variable values $f(\alpha, \beta)$ $=7.9$ and the calculated minimum number of patients was 27 per group.

STATISTICAL ANALYSIS

Descriptive statistics were calculated for all variables. The quantitative variables were summarised by mean, standard deviation, range, median, etc, and the qualitative variables were described by frequency counts and percentages. The primary and secondary efficacy variables (except complete recovery) were analysed using the analysis of variance of repeated measures. The values of variables at different times ( 6 weeks, 3 months, 6 months, and 12 months) were treated as within-subjects factors. Treatment (ciprofloxacin $v$ placebo) was considered as a between-subjects factor. The baseline (timepoint 0 ) variables were treated as covariates. The complete recovery variable was treated as the end point in a Kaplan-Meier survival analysis. The differences between the survival curves for each treatment were analysed using log rank statistics. All tests were evaluated as two sided with $\mathrm{p}<0.05$-that is, a significance level of $5 \%$, implying a statistically significant difference between the treatment groups.

\section{Results}

Seventy one patients were recruited to the study, the total number of patients in the intention-to-treat analysis was 69, and 62 of

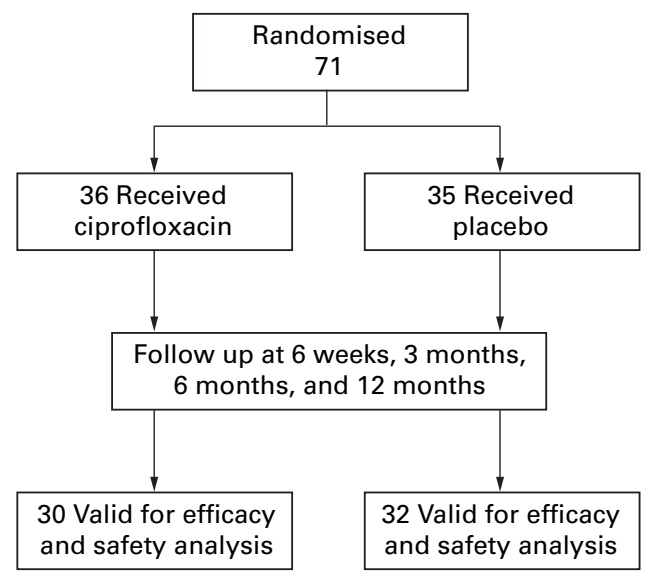

Figure 1 Trial profile. 
Table 2 Triggering microbes

\begin{tabular}{lcl}
\hline & $\begin{array}{c}\text { Ciprofloxacin group } \\
\text { No (\%) }\end{array}$ & $\begin{array}{l}\text { Placebo group } \\
\text { No (\%) }\end{array}$ \\
\hline Enteroarthritis & $30(83)$ & $30(86)$ \\
$\quad$ Salmonella & $11(31)$ & $11(31)$ \\
Yersinia & $10(28)$ & $10(29)$ \\
Campylobacter & $5(14)$ & $7(20)$ \\
Clostridium difficile & 0 & $1(3)$ \\
Undefined & $4(11)$ & $1(3)$ \\
& & $5(14)$ \\
Uroarthritis & $6(17)$ & $1(3)$ \\
Chlamydia & $2(6)$ & 0 \\
Gonorrhoea & $1(3)$ & $4(11)$ \\
Undefined & $3(8)$ & \\
\hline
\end{tabular}

these patients were valid for efficacy analysis (fig 1). Thirty (83\%) patients in the ciprofloxacin group and $30(86 \%)$ in the placebo group had enteroarthritis, six $(17 \%)$ patients in the former group and five $(14 \%)$ in the latter group had uroarthritis (table 2). The triggering microbe was salmonella in 22 patients, yersinia in 20, campylobacter in 12 , Clostridium difficile in one, Chlamydia trachomatis in three, Neisseria gonorrhoeae in one, five had preceding gastroenteritis of unknown cause, and seven preceding urethritis of unknown cause.

Twenty two of the patients with enteroarthritis (salmonella-13, Y enterocolitica III-four, campylobacter-three, Clostridium difficiletwo) had a positive fecal culture and Chlamydia
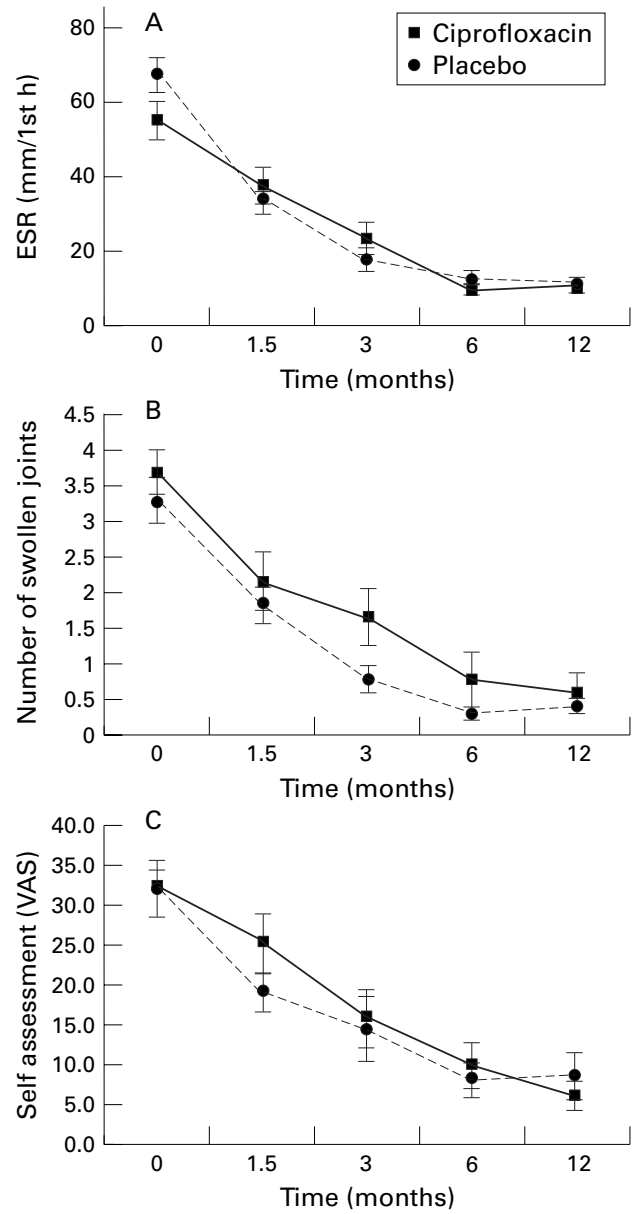

Figure 2 Changes in $(A)$ erythrocyte sedimentation rate (ESR), (B) number of swollen joints, and (C) patient global assessment in patients treated with ciprofloxacin $(n=30)$ or placebo $(n=32)$. Values are means $(S E M)$. Differences between groups over time were not significant. trachomatis DNA was detected by polymerase chain reaction in three patients. Positive serology was found in 21 of the 22 patients with salmonella, in all 20 patients with yersinia, in eight of the 12 with campylobacter, respectively. High levels of Chlamydia trachomatis IgG antibodies were detected in all three patients. Five $(8 \%)$ patients in the enteroarthrits group and seven $(64 \%)$ patients in the uroarthritis group remained undifferentiated-that is, the triggering microbe could not be identified.

No statistically significant differences were found in any of the primary (fig 2 and 3 ) or secondary efficacy variables between the study groups at baseline or during the 12 month follow up. All primary efficacy variables indicated that the condition of the patients valid for efficacy analysis improved over the study period, but between the two groups treatment had no significant effect on the changes (baseline $v$ last visit) of $\operatorname{ESR}(p=0.148)$, number of swollen joints $(p=0.281)$, patient global assessment VAS $(p=0.775)$, and complete recovery $(p=0.881)$. In the intention-to-treat analysis the results were the same as above: treatment itself had no significant effect on the changes (baseline $v$ last visit) of ESR ( $\mathrm{p}=0.57)$, number of swollen joints $(p=0.225)$, patient global assessment VAS $(\mathrm{p}=0.481)$, and complete recovery $(\mathrm{p}=0.965)$. Also, no difference was found when the groups with enteroarthritis and uroarthritis were analysed separately.

During the study all adverse events were carefully recorded, even if they did not in any apparent way correlate with the drugs used. Two serious adverse events occurred in the group receiving active treatment-one female patient had microscopic haematuria and one male patient was admitted to hospital because of high fever and prolonged arthritis of the knee. Neither of these was related to the study drug. Other adverse events were mild (table 3 ). Altogether, 22 adverse events were reported affecting the gastrointestinal tract-14 in the active group and eight in the placebo group. Two patients in the group receiving ciprofloxacin withdrew prematurely from the study-one because of diarrhoea, the other because of suspected inflammatory bowel disease. Two patients in the ciprofloxacin group had slightly raised liver enzymes (serum alanine aminotransferase) during or after the study drug (visits 2-4). The patients in the placebo group more often had bacterial infections $(p<0.05)$ than the patients in the group receiving active treatment. Adverse events affecting the nervous system were more common in the active treatment group, though the difference was not statistically significant. Other adverse events were rare and probably not related to the study drug.

During the 12 month follow up 11 (eight in the active, three in the placebo group) patients had progressive disease and antirheumatic treatment was started. Seven patients in the active group and three in the placebo group received sulfasalazine, one patient in the active group was treated with low dose methotrexate (table 4). Six patients in the ciprofloxacin group and four in the placebo group received 


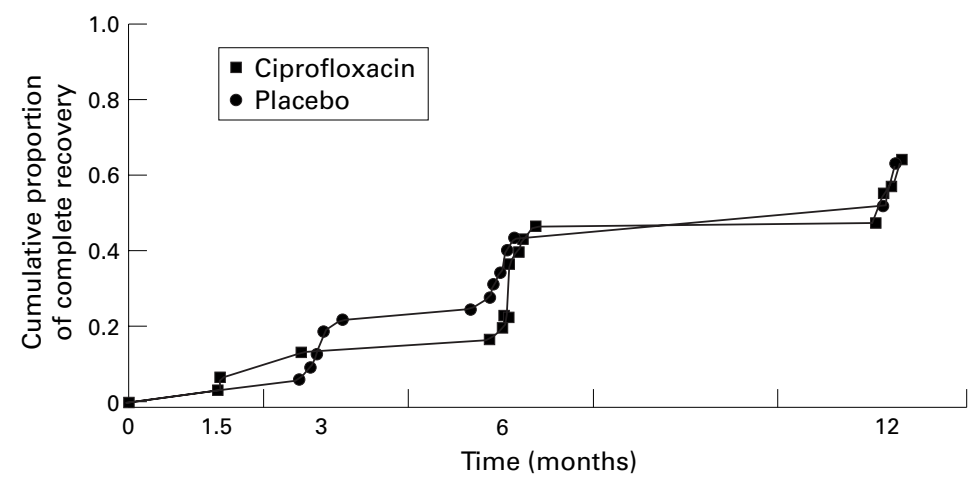

Figure 3 Cumulative proportion of patients in persistent complete remission after treatment with ciprofloxacin $(n=30)$ or placebo $(n=32)$. Differences between groups over time were not significant. appropriate antibiotic treatment. ${ }^{38}$ The incidence of post-venereal relapses of ReA was significantly reduced if new infections were rapidly treated with short term erythromycin or tetracycline, effective against chlamydial infections. ${ }^{29}$

The issue becomes more complicated if ReA has already developed. Lauhio et al reported that long term antibiotic treatment with lymecycline was beneficial in chlamydia induced arthritis. ${ }^{26}$ However, since tetracycline antibiotics have anticollagenolytic properties the effect was not necessarily due to the antimicrobial activity. ${ }^{39}$ Prolonged doxycycline treatment of chlamydia induced arthritis was no better than short term treatment in patients with chronic disease. ${ }^{40}$ Short term antibiotic treatment in ReA has definitely proved to be ineffective, ${ }^{24}$ and even treatment of enteritis did not prevent ReA. ${ }^{41}$

In this study we have evaluated the possible effect of a three month course of ciprofloxacin on ReA in acute disease. Ciprofloxacin has good penetration to tissues and a wide spectrum of antimicrobial efficacy against Gram positive and Gram negative bacteria, including intracellular organisms like chlamydia, though ciprofloxacin is not the best drug for the treatment of chlamydia infections. In chronic ReA long term ciprofloxacin treatment proved to have no clear effect on the course of disease. ${ }^{27}$ Sieper et al found no difference in the outcome between patients treated with long term ciprofloxacin or placebo, and no difference was found in a subgroup with a disease duration of less than three months. ${ }^{42}$

In our study all the patients had acute ReA. There was a clear tendency towards recovery in both treatment groups during the 12 month follow up. The conventional treatment included NSAIDs, intra-articular injections of glucocorticoid when needed, and physiotherapy in some patients. The treatment groups were comparable, the drug was well tolerated, and few patients dropped out. Thus the conduct of the study succeeded well. In most patients the disease was triggered by an enteric infection and only 11 of 71 patients with ReA had uroarthritis. In this respect the material was different from that of earlier studies. ${ }^{26} 4042$ Owing to the small number of patients with uroathritis, no definite conclusions about the possible effect of ciprofloxacin on uroarthritis can be made. In all except 12 patients the triggering infection could be defined either by culture, polymerase chain reaction or serologically.

Our findings match fully experimental animal models where yersinia triggered ReA could be cured only if the antibiotic treatment was introduced at an early phase of arthritic development, but not if the disease was fully developed. ${ }^{43}{ }^{44}$ In human medicine this fact almost always presents a problem as the patient seeks medical treatment because of ReA. Only in the unusual setting of Bardin et al was early antibiotic treatment possible and, indeed, turned out to be effective. ${ }^{29}$ In an experimental set-up ciprofloxacin treatment resulted in increased faecal excretion of yersinia in rats. ${ }^{44}$ 
Thus antibiotic treatment paradoxically might favour bacterial persistence.

If ciprofloxacin treatment is to be used for the treatment of ReA it should be based on strong evidence. It is expensive, contains the risk of side effects, and requires good compliance from the patient. In our study ciprofloxacin was safe and quite well tolerated and, in the future, long term treatment might be indicated in some other forms of chronic infectious diseases. Short term treatment with antibiotics is indicated in the eradication of primary chlamydial, gonococcal, and streptococcal infections, if it is possible to start the treatment early. In the treatment of Lyme borreliosis antibiotic eradication is effective even if started later in the course of the disease.

The conclusion from our study is clearciprofloxacin given as a three month course has no advantage over the placebo treatment.

Supported by the Emil Aaltonen foundation and the EVO gran of Turku University Central Hospital. We thank Bayer Finland Oy for the ciprofloxacin used in the study, for support in the statistical analysis, and for cooperation during the study.

All the authors contributed to the design, analysis, and writing of the report. Auli Toivanen was the principal investigator. Clinical assessments of the patients were performed by Timo Yli-Kerttula, Reijo Luukkainen, Urpo Yli-Kerttula, Timo Möttönen, Mikko Hakola, Markku Korpela, and Markku Sanila Jaakko Uksila and Raija Vainionpää carried out the serum antibody determinations. Data collection and statistical analysis were performed by Jouni Parviainen.

1 Toivanen A, Toivanen P. Aetiopathogenesis of reactive arthritis. Rheumatology in Europe 1995;24:5-8.

2 Valtonen VV, Leirisalo M, Pentikäinen PJ, Räsänen T, Seppälä I, Larinkari $\mathrm{U}$, et al. Triggering infections in reactive arthritis. Ann Rheum Dis 1985;44:399-405.

3 Yli-Kerttula T, Tertti R, Toivanen A. Ten-year follow up study of patients from a Yersinia pseudotuberculosis III study of patients from a Yersinia pseudotubercu
outbreak. Clin Exp Rheumatol 1995;13:333-7.

4 Sairanen E, Paronen I, Mähönen H. Reiter's syndrome: a Sairanen E, Paronen I, Mähönen H. Reiter's syndrom

5 Kalliomäki JL, Leino R. Follow-up studies of joint complications in yersiniosis. Acta Med Scand 1979;205: $521-5$.

6 Leirisalo-Repo $M$, Helenius $P$, Hannu T, Lehtinen A, Kreula J, Taavitsainen $\mathrm{M}$, et al. Long term prognosis of reactive salmonella arthritis. Ann Rheum Dis 1997;56 516-20.

7 Toivanen A, Toivanen P. Reactive arthritis. Boca Raton: CRC Press, 1988.

8 Herrlinger JD, Asmussen J-U. Long term prognosis in yersinia arthritis: clinical and serological findings. Ann Rheum Dis 1992;51:1332-4.

9 Keat A. Reiter's syndrome and reactive arthritis in perspective. N Engl J Med 1983;309:1606-15.

10 Mielants H, Veys EM. The gut and reactive arthritis. Rheumatology in Europe 1995;24:9-11.

11 Yli-Kerttula T, Möttönen T, Toivanen A. Different course of reactive arthritis in two HLA-B27 positive brothers with
of of reactive arthritis in two HLA-B27 positive brothers
fatal outcome in one. J Rheumatol 1997;24:2047-50.

12 Granfors K, Viljanen M, Tiilikainen A, Toivanen A. Persistence of IgM, IgG, and IgA antibodies to yersinia in Yersinia ence of IgM, IgG, and IgA antibodies
arthritis. J Infect Dis 1980;41:424-9.

13 Granfors K, Toivanen A. IgA-anti-yersinia antibodies in yersinia triggered reactive arthritis. Ann Rheum Dis 1986 45:561-5.

14 Hoogkamp-Korstanje JAA, de Koning J, Heesemann J. Persistence of Yersinia enterocolitica in man. Infection $1988 ; 16: 81-5$.

15 Lahesmaa-Rantala R, Granfors K, Isomäki H, Toivanen A Yersinia specific immune complexes in the synovial fluid of reactive arthritis. Ann Rheum Dis 1987;46:510-14

16 Lahesmaa-Rantala R, Granfors K, Toivanen A. Detection of circulating yersinia-immunoglobulin complexes by enzyme immunoassay (EIA). J Immunol Methods 1986;89:191-9.

17 Granfors K, Jalkanen S, Linberg AA, Mäki-Ikola O, von Essen R, Lahesmaa-Rantala R, et al. Salmonella lipopolyEssen R, Lahesmaa-Rantala $R$, et al. Salmonella lipopolysaccharide in synovial cells from
arthritis. Lancet 1990;335:685-8.

18 Granfors K, Jalkanen S, Toivanen P, Koski J, Linberg AA. Bacterial lipopolysaccharide in synovial fluid cells in shigella triggered reactive arthritis. J Rheumatol 1992;19: 500

19 Keat A, Thomas B, Dixey J, Osborn M, Sonnex C, Taylor Robinson D. Chlamydia trachomatis and reactive arthritis: the missing link. Lancet 1987;i:72-4.
20 Schumacher HR, Magge S, Cherian PV, Sleckman J, Rothfuss S, Clayburne G, et al. Light and electron microscopic studies on the synovial membrane in Reiter's syndrome, Immunocytochemical identification of chlamydial antigen in patents with early disease. Arthritis Rheum 1988;31: 937-46.

21 Sieper J, Braun J, Brandt J, Miksits K, Heesemann J, Laitko $\mathrm{S}$, et al. Pathogenetic role of chlamydia, yersinia and borrelia in undifferentiated oligoarthritis. J Rheumatol 1992;19: 1236-42.

22 Hammer M, Nettelnbreker E, Hopf S, Schmitz E, Pörschke $\mathrm{K}$, Zeidler H. Chlamydial rRNA in the joints of patients with chlamydia-induced arthritis and undifferentiated with chlamydia-induced arthritis and undif

23 Clegg DO, Reda DJ, Weisman MH, Cush JJ, Vasey FB, Schumacher HR, et al. Comparison of sulfasalazine and Schumacher HR, et al. Comparison of sulfasalazine and
placebo in the treatment of reactive arthritis (Reiter's syndrome). Arthritis Rheum 1996;39:2021-7.

24 Frydén A, Bengtsson A, Foberg U, Svenungsson B, Castor $\mathrm{B}$, Kärnell A, et al. Early antibiotic treatment of reactive arthritis associated with enteric infections: clinical and serological study. BMJ 1990;301:1299-302.

25 Kihlström E, Foberg U, Bengtsson A, Fryden A, Svenungsson B, Schvarcz R, et al. Intestinal symptoms and serological response in patients with complicated and uncomplicated Yersinia enterocolitica infections. Scand J Infect Dis 1992;24:57-63.

26 Lauhio A, Leirisalo-Repo M, Lähdevirta J, Saikku P, Repo H. Double-blind, placebo-controlled study of three-month treatment with lymecycline in reactive arthritis, with special reference to Chlamydia arthritis. Arthritis Rheum 1991;34: 6-14.

27 Toivanen A, Yli-Kerttula T, Luukkainen R, Merilahti-Palo R, Granfors K, Seppälä J. Effect of antimicrobial treatment on chronic reactive arthritis. Clin Exp Rheumatol 1993;11: 301-7.

28 Hoogkamp-Korstanje JAA. Antibiotics in Yersinia enterocolitica infections. J Antimicrob Chemother 1987;20:123-31.

29 Bardin T, Enel C, Cornelis F, Salski C, Jorgensen C, Ward $\mathrm{R}$, et al. Antibiotic treatment of venereal disease and Reiter's syndrome in a Greenland population. Arthritis Rheum 1992;35:190-4.

30 Barry AL, Jones RN, Thornsberry C, Ayers LW, Gerlach LH, Sommers HM. Antibacterial activities of ciprofloxacin, norfloxacin, oxolinic acid, cinoxacin, and nalidixic acid. Antimicrob Agents Chemother 1984;25:633-7.

31 Ritchie DM, Boyle JA, McInnes JM, Jasani MK, Dalakos TG, Grieveson P, et al. Clinical studies with an articular index for the assessment of joint tenderness in patients with rheumatoid arthritis. Q J Med 1968;147:393-406.

32 Isomäki O, Vuento R, Granfors K. Serological diagnosis of salmonella infections by enzyme immunoassay. Lancet 1989; i: 1411-14.

33 Granfors K, Lahesmaa-Rantala R, Ståhlberg TH, Toivanen A. Comparison of bacteria with and without plasmidencoded proteins as antigens for measurement of immunoglobulin $M, G$ and $A$ antibodies to Yersinia enterocolitica by enzyme-linked immunosorbent assay. J Clin Microbiol 1989;27:583-5.

34 Kosunen TU, Rautelin H, Pitkänen T, Pönkä A, Pettersson T. Antibodies against an acid extract from a single campylobacter strain in hospitalized campylobacter patients. Infection 1983;11:189-91.

35 Finn MP, Ohlin A, Sachter J. Enzyme-linked immunosorbent assay for immunoglobulin $G$ and $M$ antibodies to Chlamydia trachomatis in human sera. J Clin Microbiol 1983;17:848-52.

36 Nanagara R, Li F, Beutler A, Hudson A, Schumacher HR. Alteration of Chlamydia trachomatis biologic behavior in synovial membranes. Suppression of surface antigen production in reactive arthritis and Reiter's syndrome. Arthritis Rheum 1995;38:1410-17.

37 Lue HC, Wu MH, Wang JK, Wu FF, Wu YN. Long-term outcome of patients with rheumatic fever receiving benzathine penicillin $G$ prophylaxis every three weeks versus every four weeks. J Pediatr 1994;125:812-16.

38 Steere AC, Levin RE, Molloy PJ, Kalish RA, Abraham JH, Liu NY, et al. Treatment of Lyme arthritis. Arthritis Rheum 1994;37:878-88.

39 Lauhio A, Sorsa T, Lindy O, Suomalainen K, Saari H, Golub LM, et al. The anticollagenolytic potential of lymecycline in the long-term treatment of reactive arthritis. Arthritis Rheum 1992;35:195-8.

40 Wollenhaupt J, Hammer M, Pott HG, Zeidler H. A doubleblind placebo-controlled comparison of 2 weeks versus 4 months treatment with doxycycline in chlamydia-induced arthritis. Arthritis Rheum 1997;40:S143.

41 Locht H, Kihlström E, Lindström FD. Reactive arthritis after salmonella among medical doctors - study of an outbreak. J Rheumatol 1993;20:845-8.

42 Sieper J, Fendler C, Laitko S, Sörensen H, GripenbergLerche $\mathrm{C}$, Hiepe $\mathrm{F}$, et al. No benefit of long-term ciprofloxacin treatment in patients with reactive arthritis and undifferentiated oligoarthritis. Arthritis Rheum 1999; 42:1386-96.

43 Zhang Y, Gripenberg-Lerche C, Söderström K-O, Toivanen A, Toivanen P. Antibiotic prophylaxis and treatment of reactive arthritis. Arthritis Rheum 1996;39:1238-43.

44 Zhang Y, Toivanen A, Toivanen P. Experimental yersiniatriggered reactive arthritis: effect of a 3-week course of ciprofloxacin. Br J Rheumatol 1997;36:541-6. 